\title{
Narrativa
}

narrativa

Nuova serie

$43 \mid 2021$

La fantascienza nelle narrazioni italiane ipercontemporanee

\section{Giuliana ZAGRA, La tela favolosa. Carte e libri sulla scrivania di Elsa Morante}

\section{Ada D'Agostino}

\section{OpenEdition}

1 Journals

Edizione digitale

URL: https://journals.openedition.org/narrativa/501

DOI: $10.4000 /$ narrativa.501

ISSN: 2804-1224

Editore

Presses universitaires de Paris Nanterre

\section{Edizione cartacea}

Data di pubblicazione: 1 décembre 2021

Paginazione: 308-309

ISBN: 978-2-84016-485-2

ISSN: $1166-3243$

Notizia bibliografica digitale

Ada D'Agostino, "Giuliana zagra, La tela favolosa. Carte e libri sulla scrivania di Elsa Morante », Narrativa [Online], 43 | 2021, online dal 01 novembre 2021, consultato il 03 novembre 2022. URL: http:// journals.openedition.org/narrativa/501; DOI: https://doi.org/10.4000/narrativa.501

Questo documento è stato generato automaticamente il 3 novembre 2022

Creative Commons - Attribuzione 4.0 Internazionale - CC BY 4.0

https://creativecommons.org/licenses/by/4.0/ 


\title{
Giuliana ZAGRA, La tela favolosa. Carte e libri sulla scrivania di Elsa Morante
}

\author{
Ada D'Agostino
}

\section{NOTIZIA}

Giuliana ZAGRA, La tela favolosa. Carte e libri sulla scrivania di Elsa Morante, Roma, Carocci editore, 2019, $134 \mathrm{p}$.

1 Il libro di Giuliana Zagra ripercorre l'itinerario della scrittura di Elsa Morante a partire da un'angolatura inedita e quanto mai necessaria: l'insieme delle carte che danno forma all'archivio dell'autrice. Costruito nel corso di oltre venticinque anni grazie a una serie di donazioni successive e consultabile presso la Biblioteca nazionale di Roma, quello morantiano rappresenta, per dirla con Zagra, "l'archivio di tutta la vita": dai quaderni contenenti i primi raccontini di Elsa, enfant prodige della scrittura, all'ultimo breve appunto registrato dalle pagine del taccuino, nel 1985, l'attività di quasi settant'anni di scrittura è raccontata e spesso illuminata da una ricchissima mole di documenti.

2 Le carte sembrano essere percorse da una duplice tensione: all'immagine di Morante come donna schiva e misteriosa si oppone infatti con forza quella dell'autrice "archivista di se stessa", curatrice attenta dei materiali che consegnano la sua storia al lettore futuro. Una stessa scissione sottende del resto anche le opere, che Morante vorrebbe sfrondare da ogni implicazione biografica, e che affondano al contrario le loro radici in una serie di vicende intimamente private. L'intreccio tra scrittura ed esperienza biografica è reso evidente dalla lettura dei documenti inediti, che svelano come il farsi dei romanzi risponda in primo luogo, e di volta in volta, a un'intrinseca e personalissima necessità.

3 I sei capitoli del libro di Zagra seguono in questo senso una scansione latamente cronologica: i grandi romanzi di Morante sono presentati secondo dei precisi punti di intersezione con le carte inedite, in grado di svelare importanti aspetti della genesi 
delle opere. Così, ad esempio, due dei temi nodali di Menzogna e sortilegio, "la morte del padre" e "gli amori crudeli", sembrano traslare sul piano letterario le vicende vissute in prima persona da Morante. Ancora, l'archivio mostra come L'isola di Arturo trovi nutrimento - e forse, in parte, le ragioni del suo farsi - nella necessità di elaborare un'esperienza dolorosamente privata. Rispetto a questo romanzo, le carte riservano inoltre la sorpresa di un diverso incipit; o meglio, di " 40 prove scartate" di un iniziale incipit alternativo. Non è l'unico dato inatteso che i materiali lasciano emergere. Zagra sottolinea ad esempio come i manoscritti del Mondo salvato dai ragazzini (1968) scompaginino il tradizionale metodo di lavoro morantiano, decretando anche da questo punto di vista l'indubbia originalità del testo. Diverse sono poi le prove di romanzo rimaste incompiute e riportate alla luce dall'archivio. Più ancora che la loro presenza, colpisce il sistematico trasmigrare di temi e abbozzi di alcuni personaggi nelle opere successive: è quanto accade con Superman, che anticipa "temi e caratteri del protagonista" di Aracoeli; e, in maniera più evidente, con Senza i conforti della religione, "punto di snodo" più che "progetto incompiuto", da considerare per tanti versi come antecedente del romanzo La storia. Proseguendo la stessa tipologia di indagine, il quinto capitolo scandaglia con maggiore profondità il legame tra il romanzo abbandonato Nerina e la raccolta di racconti Lo sciallo andaluso, in cui la storia di Andreuccio, estrapolata dal vecchio progetto di romanzo, viene recuperata e resa racconto autonomo.

4 Le carte, infine, permettono di osservare il metodo di lavoro dell'autrice, preciso e puntualissimo, rappresentato in forma compiuta dalla serie dei quaderni. La divisione tra recto e verso (l'uno destinato alla stesura delle opere, l'altro riservato a commenti e revisioni) ripropone quello "sdoppiamento dialogante" che definisce in egual misura il rapporto tra Elsa Morante e la lettura. A chiudere il saggio di Zagra è appunto una panoramica sulla libreria e sulla raccolta di dischi dell'autrice, da considerarsi entrambe, a loro volta, parte integrante della genesi dei romanzi.

A conti fatti, il libro di Zagra sembra delineare l'immagine dell'archivio di Elsa Morante come organismo vivo, poroso, metamorfico, in grado di estrapolare da ogni vicenda e ogni scritto abbandonato nuova linfa per progetti futuri. Uno specchio capace di rimandarci il senso di una continua evoluzione, che fonde nello spazio di un'unica superficie esperienze di vita e di scrittura. 